\title{
Efficient phenol removal from aqueous solution using iron-coated pumice and leca as an available adsorbents: evalution of kinetics and isotherm studies
}

\author{
Shokoohi R. ${ }^{1}$, Torkshavand Z. ${ }^{2}$, Bajalan S. ${ }^{3}$, Zolghadnasab H. ${ }^{3}$ and Khodayari Z. ${ }^{3 *}$ \\ ${ }^{1}$ Department of Environmental Health Engineering, School of Public Health, Hamadan University of Medical Sciences, Hamadan, Iran \\ ${ }^{2} \mathrm{PhD}$ Student of Environmental Health Engineering, School of Public Health, Hamadan University of Medical Sciences, Hamadan, Iran \\ ${ }^{3} \mathrm{MSc}$ Student of Environmental Health Engineering, Faculty of Public Health, University of Medical Science, Hamadan, Iran \\ Received: 30/05/2018, Accepted: 22/10/2018, Available online: 31/10/2018 \\ *to whom all correspondence should be addressed: e-mail: khodayaridarya@yahoo.com \\ https://doi.org/10.30955/gnj.002783
}

\begin{abstract}
Searching for low cost, accessible, simple implementation, and environmentally friendly adsorbents has been one of the concern of researchers in recent years. Therefore, the aim of this study was to investigate the efficient phenol removal from a synthetic aqueous solution using ironcoated pumice and LECA as an available adsorbents. Bath adsorption experiments were carried out to evaluate the effects of the independent variables such as $\mathrm{pH}$ (3-5-7-911), initial concentration of phenol $(10-50 \mathrm{mg} / \mathrm{L})$, contact time (10-60 $\mathrm{min})$ and different concentrations of pumice and LECA $(0.2-1 \mathrm{~g} / 100 \mathrm{cc})$ on the phenol adsorption. The results of the experiments showed that there was a direct relationship between the phenol removal efficiency and increasing the contact time and the adsorbent dosage but it has reverse relationship with the increasing of $\mathrm{pH}$ and phenol initial concentration. The optimal condition of parameters for phenol removal were 200 rpm agitation speed, $0.6 \mathrm{~g}$ adsorbent dosage, 30 min contact time, and $20 \mathrm{mg} / \mathrm{L}$ initial phenol concentration. The study of isotherm and kinetic models showed that the experimental data of the phenol adsorption process were correlated with Freundlich $\left(R^{2}\right.$ pumice $=0.9749, R^{2}$ LECA $\left.=0.9487\right)$ and Pseudo-second order $\left(R^{2}\right.$ pumice $=0.9745, R^{2}$ LECA $\left.=0.9486\right)$ models. Based on this study's results, the modified pumice and LECA have a high ability to remove the phenol compounds from aqueous solution.
\end{abstract}

Keywords: Phenol removal, adsorption, pumice stone, light expanded clay aggregate, aqueous solution.

\section{Introduction}

With the rapid expansion of industries and industrialization of societies, the water resources are influenced by various pollutants. Among various water resources pollutants, the phenol and phenolic compounds are categorized as the priority pollutants, which are considered to be a serious threat to human health and aquatic organisms (Wang et al., 2018). Phenolic compounds are a large group of aromatic hydrocarbons that are flammable and can extensively dissolve in water, oil and some organic solvents (Shokoohia et al., 2017). This compound and its derivatives are found in a variety of industries such as paint, pesticides, polymer resins, oil and petrochemical, paper, rubber, textiles, and wood (Ahmaruzzaman, 2008; Rao and Viraraghavan, 2002; Messele et al., 2017). The allowable amount of phenol compounds for drinking water and wastewater discharged to the environment is 0.001 and $1 \mathrm{mg} / \mathrm{L}$ (EPA, 2009). For this purpose, different methods such as oxidation, adsorption, ion exchange, solvent extraction, biological treatment and precipitation have been used to remove the phenol compound from aqueous solutions (Hameed and Rahman, 2008; Rengaraj et al., 2002; Aksu and Yener, 2001). The adsorption process among these techniques has found more popularity than other methods in terms of initial cost, simplicity, flexibility, easy operation, insensitivity to toxic compounds, high potential for removal of organic and inorganic compounds even at lower concentrations (Abussaud et al., 2016). Various materials such as activated carbon (Abussaud et al., 2016), coconut shell (Din et al., 2009), single-walled and multi-walled carbon nanotubes (Dehghani et al., 2016) and chitin (Dursun and Kalayci, 2005) have been used for the phenol removal from aqueous solutions. However, the use of low-cost and local adsorbents for pollutant removal is highly interesting (Heibati et al., 2016). For this purpose, several studies have been conducted on the use of the pumice or LECA as an local low-cost in both natural and modified forms, to remove the pollutants such as phenol and 4-chlorophenol (Akbal, 2005a), cadmium (Panuccio et al., 2009), fluoride (Asgari et al., 2012), basic dyes (Akbal, 2005b), heavy metals (Malakootian et al., 2009), from aqueous solution (Asgari et al., 2012). Pumice stone is a porous igneous volcanic rock, with significant accessibility, which it is abundantly found in nature and considered as an inexpensive adsorbent (Asgari et al., 2012; Akbal, 2005b). 
LECA has derived from the phrase of light expanded clay aggregate. It is produced in a rotary kiln and at a temperature of $1200^{\circ} \mathrm{C}$, due to the expansion of a particular type of clay. Due to features such as lightness, sound insulation, temperature and moisture insulation, incompressibility against constant pressure, nondegradability, heat-resistant, its natural structure, production in the country and lower cost than industrial adsorbents, it can be used as a suitable, inexpensive and environmentally friendly adsorbent (Nkansah et al., 2012). According to availability the numerous pumice and LECA mines in Iran, especially in Kurdistan province of Iran, the main objective of this study was investigate the efficiency of pumice and LECA coated with iron nanoparticles in removing the phenol from aqueous environments. Moreover, the effect of independent variables such as $\mathrm{pH}$, initial phenol concentration, contact time and different dosage of pumice and LECA on the phenol removal efficiency in a batch reactor was investigated. Finally, isotherm models, i.e., the Freundlich and Langmuir models, and the kinetic models, i.e., pseudo-first-order and pseudo-second-order models were investigated to determine the equilibrium constant of reaction and the adsorption kinetic.

\section{Materials and methods}

\subsection{Adsorption experiments in batch conditions}

In this research, the efficiency of adsorption process using pumice and LECA coated with iron nanoparticles in removing phenol from aqueous solution were studied in batch procedure and laboratory scale. Experiments were carried out in $250 \mathrm{~mL}$ Erlenmeyer Flask containing specific amounts of adsorbent and various concentration of pollutant at the different $\mathrm{pH}$ and time. To create the proper mixing between adsorbent and adsorbate in all samples studied, a shaker at $150 \mathrm{rpm}$ was used. In order to optimize the experiment conditions, the effect of $\mathrm{pH}$ and contact time on the phenol adsorption process was investigated at $\mathrm{pH}$ values of 3-11 and the contact time of 10-60 min, and the optimum contact time and $\mathrm{pH}$ were determined. Determination of optimum $\mathrm{pH}$ and time was performed at the constant values of initial phenol concentration $(30 \mathrm{mg} / \mathrm{L})$ and adsorbent dosage $(0.6 \mathrm{~g} / 100 \mathrm{cc})$. In the next step, after optimizing the $\mathrm{pH}$ and contact time, the effect of initial phenol concentration inrange of $10-50 \mathrm{mg} / \mathrm{L}$ and the adsorbent dosage of 0.1-2.0 gr on the phenol removal efficiency was studied. Finally, the isotherms and kinetics of phenol adsorption onto the pumice and LECA coated with iron nanoparticles were separately determined. All materials used in this study were provided from Merck CO and data analysis was performed by Excel software. Phenol concentrations in the studied samples were measured using the 4-Aminoantipyrine colorimetric method by a UV/VIS spectrophotometer (Shimadzo-1700, Japan) at a wavelength of $500 \mathrm{~nm}$ (W.E. Federation and A.P.H. Association, 2005). All the adsorption expriments were carried out three times and their mean values were used as the final results in the calculations.

\subsection{Preparation and characterizaion of pumice and LECA adsorbents}

The LECA and pumice adsorbents used in this study was obtained from Ghorveh area, Kurdistan province, Iran. In order to increase the porosity and remove the impurities, the adsorbent was exposed to $0.1 \mathrm{M}$ sulfuric acid for $24 \mathrm{~h}$ and then washed with distilled water and dried in an oven at $105^{\circ} \mathrm{C}$ for $24 \mathrm{~h}$. Afterward, this acid-washed adsrobent was used for the coating process. The desired particle size (mesh 80) of adsorbents was obtained from sieve pumice and LECA which had been grinded previously. In the next step, to modify the adsorbent particles, they were placed in $1 \mathrm{M}$ iron nitrate solution. So that, while the iron nitrate solution was stirred at $200 \mathrm{rpm}$, a $0.5 \mathrm{M} \mathrm{NaOH}$ solution was added until the $\mathrm{pH}$ reached $9.5 \pm 1$ and mixed for $5 \mathrm{~min}$. The $100 \mathrm{gr}$ of adsorbent was then added into the solution, and the resulting mixture was placed at $60^{\circ} \mathrm{C}$ and $200 \mathrm{rpm}$ for $24 \mathrm{~h}$ and finally dried in an oven at $105^{\circ} \mathrm{C}$ for $24 \mathrm{~h}$. After that, the resutant particles were washed with distilled water several times and were dried at $60^{\circ} \mathrm{C}$. The adsorbent was kept in the polyethylene container at room temperature and kept away from light during the experiments (Asgari et al., 2012; Nkansah et al., 2012; Lee et al., 2012; Eren, 2009). In order to investigate the shape, the mean particle diameter and details of the modified adsorbents surface, the scanning electron microscopy (SEM) were utilized. X-ray diffraction (XRD) was also used to determine their crystalline structure and FTIR was used to study the functional groups on the surface of the particles.

\section{Discussion and conclusion}

\subsection{Effect of the solution $\mathrm{pH}$ in the process of phenol} adsorption from aqueous solution

The solution $\mathrm{pH}$ is one of the main parameters that influence the removal efficiency in the oxidationreduction and adsorption process (Sepehr et al., 2013). In order to investigate the effect of $\mathrm{pH}$ in the phenol removal from aqueous solution, a concentration of $30 \mathrm{mg} / \mathrm{L}$ of the solution was studied at various $\mathrm{pH}$ values of $3,5,7,9$ and 11 , the adsorbent dose of $0.6 \mathrm{~g} / 100 \mathrm{cc}$ at $150 \mathrm{rpm}$ (Figures 1 and 2). Then, at different intervals (10-60 min), the sample was taken from the solution and all samples were centrifuged for $10 \mathrm{~min}$ at $3000 \mathrm{rpm}$ with a sigma-301 centrifuge device prior to measure the residual concentration of phenol. Based on the results, the phenol adsorption onto the LECA and pumice adsorbents is increased by increasing the contact time and this increase in adsorption continues for $30 \mathrm{~min}$, and then the adsorption rate remains somewhat constant. As shown in Figures 1 and 2, with increasing $\mathrm{pH}$ from 3 to 11, the phenol removal efficiency by pumice and LECA adsorbents decreased from $99.12 \%$ to $67.12 \%$ and from $99.12 \%$ to $76.01 \%$, respectively. Therefore, the $\mathrm{pH} 3$ and the contact time of $30 \mathrm{~min}$ were used as optimum values in other experiments. In this study, the highest phenol adsorption by pumice and LECA occurred at $\mathrm{pH} 3$, which this is due to the effect of the hydrogen positive ions in acidic state on the adsorbents surface and the establishment of 
electrostatic bond between adsorbents with positive charge and the phenol which has a negative surface charge. At high and alkaline $\mathrm{pH}$ values, the removal efficiency is dramatically reduced, which this reduction in the removal efficiency is due to the competition between negative ions of hydroxyl and phenol to react with adsorbents; so that, at higher $\mathrm{pH}$ values, the hydroxyl ions concentration is greater, and this will reduce the efficiency (Wang et al., 2008). In addition, the results indicate that the adsorption rate and the rate of equilibrium are higher in the pumice adsorbent compared to the LECA. After $30 \mathrm{~min}$, it is almost possible to say that the LECA and pumice adsorbents are saturated and should be regenerated or replaced with other suitable adsorbents to remove the pollutant. The results of this study are somewhat different from the results of studies by some researchers. The study conducted by Ghader to investigate the phenol adsorption onto activated carbon showed that the equilibrium time is observed after 15 min using the activated carbon, which it is inconsistent with the results of this study (Qadeer and Rehan, 2002).

Table 1. Langmuir and Freundlich isotherm parameters

\begin{tabular}{|c|c|c|c|c|c|c|}
\hline \multirow{2}{*}{ Absorbent type } & \multicolumn{3}{|c|}{ Langmuir equation } & \multicolumn{3}{|c|}{ Freundlich equation } \\
\hline & $q_{m}(m g / g)$ & b (L/mg) & $\mathbf{R}^{\mathbf{2}}$ & $k_{f}(\mathrm{mg} / \mathrm{g})$ & $n$ & $\mathbf{R}^{2}$ \\
\hline Pumice stone & 0.392 & 0.222 & 0.9297 & 0.1 & 2.99 & 0.9749 \\
\hline LECA & 0.358 & 0.2 & 0.8007 & 0.09 & 2.6 & 0.9487 \\
\hline
\end{tabular}

Table 2. Obtained parameters of kinetic models for modified pumice stone and LECA

\begin{tabular}{ccccccc}
\hline \multirow{2}{*}{ Absorbent type } & \multicolumn{3}{c}{ Pseudo-first-order } & \multicolumn{2}{c}{ Pseudo-second-order } \\
\cline { 2 - 7 } & $\mathbf{k}_{\mathbf{1}}$ & $\mathbf{q}$ & $\mathbf{R}^{\mathbf{2}}$ & $\mathbf{K}_{\mathbf{2}}$ & $\mathbf{q}_{\mathbf{e}}$ & $\mathbf{\mathbf { R } ^ { \mathbf { 2 } }}$ \\
\hline Pumice stone & 0.0121 & 4.35 & 0.9031 & 0.0067 & 6.97 & 0.9745 \\
\hline LECA & 0.0155 & 2.53 & 0.8579 & 0.017 & 6.47 & 0.9486 \\
\hline
\end{tabular}

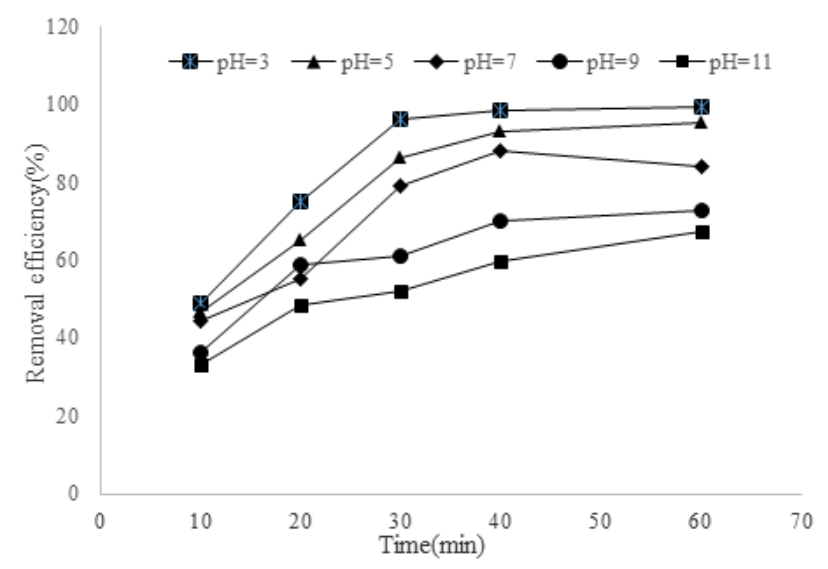

Figure 1. Effect of solution $\mathrm{pH}$ on adsorption of phenol onto modified pumice stone (phenol concentration $=30 \mathrm{mg} / \mathrm{L}$, adsorbent dose $=0.6 \mathrm{~g} / 100 \mathrm{cc}$ )

\subsection{The effect of phenol initial concentration on the adsorption process}

In order to investigate the effect of phenol concentration on the removal efficiency by LECA and pumice adsorbents, the concentration of $10,20,30,40$ and $50 \mathrm{mg} / \mathrm{L}$ of phenol were prepared and studied using adsorbent dosage of $0.6 \mathrm{~g} / 100 \mathrm{cc}$, at contact time of $30 \mathrm{~min}$ and optimum $\mathrm{pH}$ $(\mathrm{pH}=3)$ (Figure 3). As can be seen in the Figure 3, the phenol removal efficiency by the adsorbents increased with increasing the initial phenol concentration up to a concentration of $30 \mathrm{mg} / \mathrm{L}$, and, subsequently, had a small reduction. The results of this study indicate that the amount of phenol adsorption onto the adsorbents depends on its initial concentration. The phenol removal efficiency is noticeable at low concentrations, but its efficiency decreases with increasing the concentrations. The reason for these conditions is due to the filling the adsorption capacity of adsorbents, which reduces the adsorbent efficiency at higher concentrations. The results of the present study are consistent with the research carried out by Varghese et al. (2004).

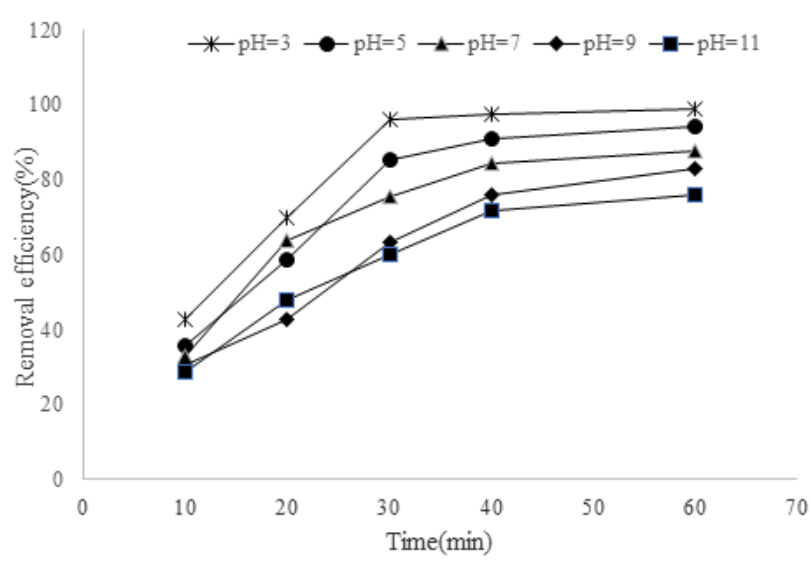

Figure 2. Effect of solution $\mathrm{pH}$ on adsorption of phenol onto modified LECA (phenol concentration $=30 \mathrm{mg} / \mathrm{L}$, adsorbent dose $=0.6 \mathrm{~g} / 100 \mathrm{cc}$ )

\subsection{Effect of adsorbent dosage on the adsorption efficiency}

At this step, after optimizing $\mathrm{pH}$, initial phenol concentration and contact time in the previous steps, the phenol adsorption by modified pumice and LECA with different adsorbent dosage $(0.2-1 \mathrm{~g} / \mathrm{L})$ were investigated (Figure 4). As shown in Figure 4 , by increasing the adsorbent dosage from 0.2 to $1 \mathrm{~g}$ in $100 \mathrm{ml}$, the phenol removal efficiency by pumice and LECA increases from $65.70 \%$ to $99.81 \%$ and from 69.94 to $99.76 \%$, respectively. The above results were obtained at an optimal $\mathrm{pH}$ of 3 and an optimum time of $30 \mathrm{~min}$. This increase in efficiency can be attributed to an increase in the active surface available for the pollutant. Although, increasing the adsorbent dosage is led to enhance the removal 
efficiency, but the amount of adsorption per unit mass (adsorption capacity) decreases due to the saturation of some of the sites on the adsorbent surface (Asmaly et al., 2016). The similar results were observed in a study which it was conducted by Abussaud et al for adsorption of phenol by activated carbon impregnated with iron oxide, aluminum oxide and titanium oxide (Abussaud et al., 2016).

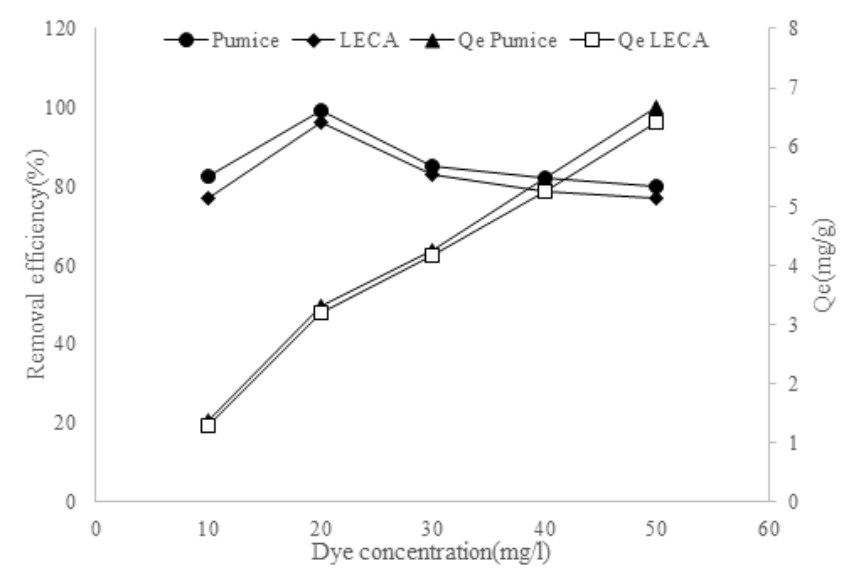

Figure 3. Effect of initial phenol concentration on phenol adsorption onto pumice and LECA adsorbent $(\mathrm{pH}=3$, adsorbent dose $=0.6 \mathrm{~g} / 100 \mathrm{cc}$, contact time $=30 \mathrm{~min}$ )

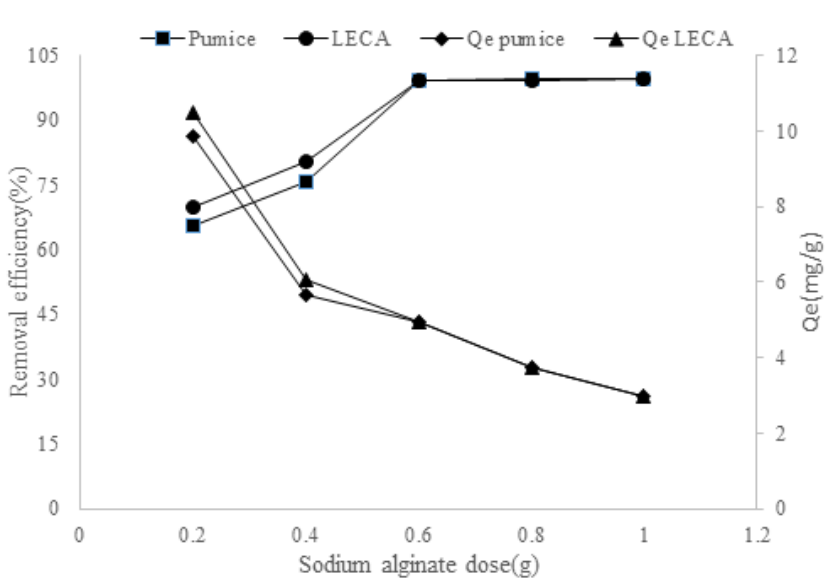

Figure 4. Effect of adsorbent dose onto percentage removal of phenol onto $(\mathrm{pH}=3$, contact time $=30 \mathrm{~min}$, phenol concentration $=20 \mathrm{mg} / \mathrm{L}$ )

\subsection{Isotherms of phenol adsorption onto pumice and LECA adsorbent}

Two Langmuir and Freundlich isotherms are widely used to study the adsorption process. The Langmuir isotherm model is based on the single-layer adsorption in a limited number of identical sites. In this model, it is assumed that adsorption takes place in the sites with the same energy that are located on the surface of the adsorbent, while, in the Freundlich isotherm model, it is assumed that the soluble matter is adsorbed on heterogeneous and multilayer surfaces (Li et al., 2012; Kırbıyık et al., 2017). The adsorption isotherm parameters are expressed in terms of adsorption capacity of the adsorbents. The constant and specific values in the isotherm represent the adsorption surface properties and can be used to compare the adsorption capacity of adsorbent for different pollutants (Behnamfard and Salarirad, 2009). Figures 5 $(5 a, 5 b)$ show the results of matching the phenol adsorption equilibrium data with the isothermal models. The phenol removal reactions by pumice $\left(R^{2}=0.975\right)$ and LECA $\left(R^{2}=0.981\right)$ has a better correspondence with Freundlich isotherm. These results show that the phenol adsorption onto the adsorbents is multi-layer and the surface of the adsorbents is heterogeneous (Li et al., 2018). According to Table 1 , the low $q_{\max }$ values of pumice and LECA indicate that their effectiveness in removing the phenol is weak. On the other hand, the amount of $R_{L}$ obtained for the reactions performed is less than 1 , which indicates that phenol adsorption on the adsorbents is undesirable (Lorenc-Grabowska et al., 2013). The results of study by Jun et al. (2017) showed that the phenol adsorption onto activated carbon derived from coal residues corresponds to the Langmuir isotherm, which it is inconsistent with results of this study (Wang et al., 2018).

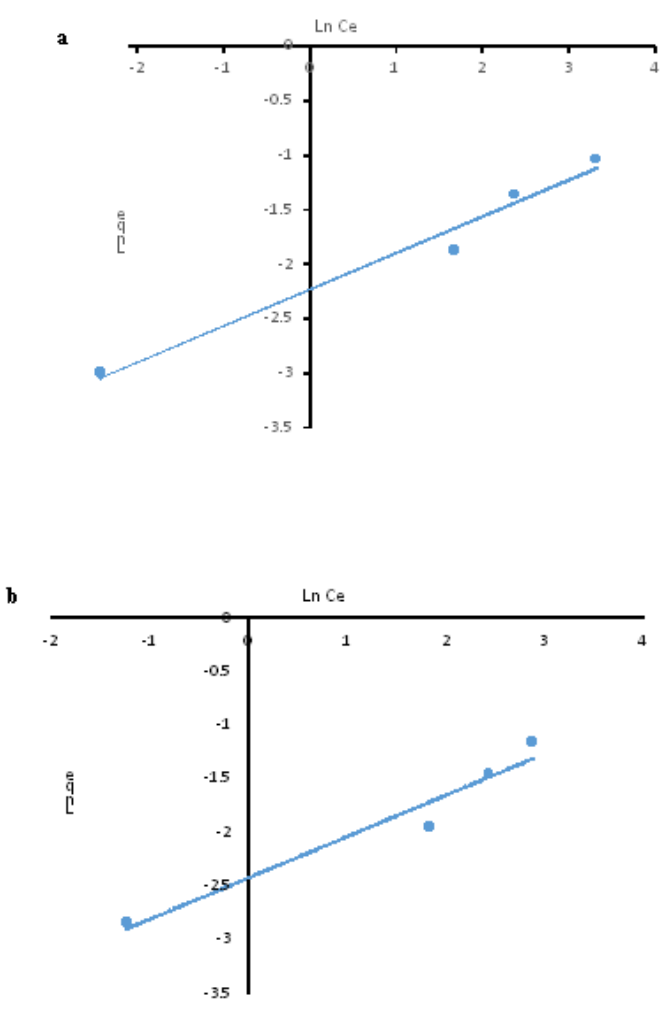

Figure 5. Freundlich isotherms plot for adsorption of phenol (a: adsorption of phenol onto modified pumice stone, b: modified LECA)

\subsection{Kinetics of phenol adsorption by pumice and LECA adsorbents}

The adsorption kinetics give important information about the adsorption mechanism, the adsorption rate of the adsorbent and the control of time in the adsorption process (Zhu et al., 2010). The dependence of the reaction rate on the initial phenol concentration was evaluated by the assumption of a pseudo-first-order and pseudosecond-order model. The pseudo-first-order model 
assumes that adsorption occurs only by a process or mechanism and in the same type of adsorption sites. Since, in this model, there are numerous adsorption sites and also there may be the mass transfer effect, therefore it seems that it is not appropriate for heterogeneous surfaces. The pseudo-second-order model is based on the assumption that the speed limiting may be a chemical uptake including the valence forces through the sharing or exchanging an electron between the adsorbent and adsorbate. Unlike the pseudo-first-order equation, this model can adequately predict the adsorption behavior during the adsorption time (Kučić et al., 2011). As shown in Figures $6 a$ and $6 b$, the phenol adsorption process onto LECA and pumice meets the pseudo-second order kinetics with the correlation coefficients higher than 0.9. This result shows that the mechanism of phenol adsorption on the adsorbents can be physical adsorption (Kučić et al., 2011). The results of this study are consistent with the study by Abdelwahab et al. (2013).
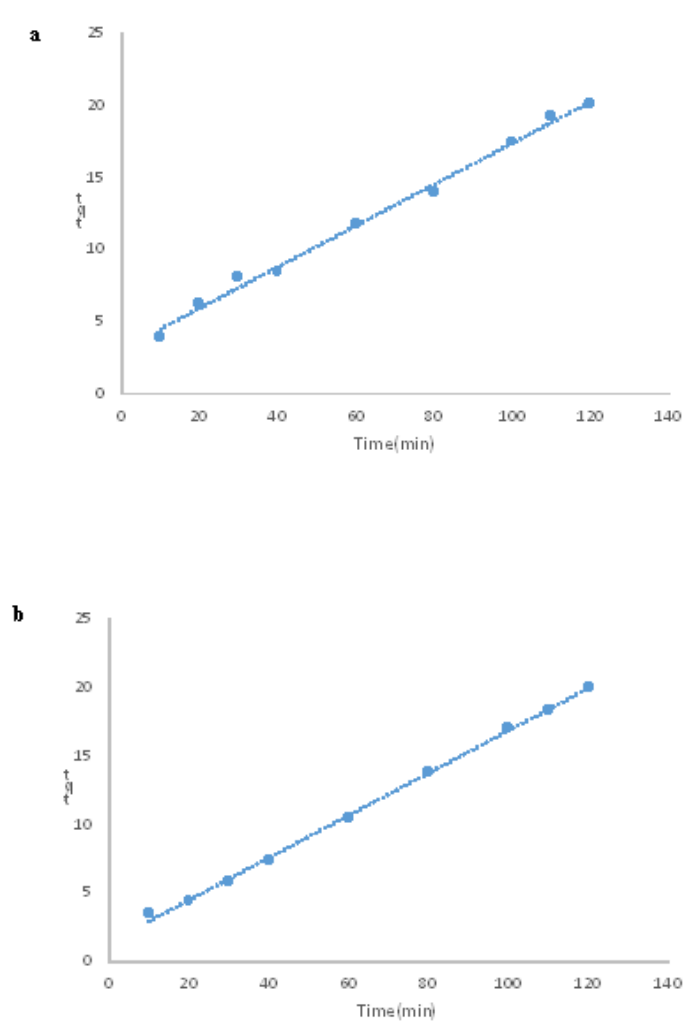

Figure 6. The fitting of obtained data onto pseudo-second-order plot for adsorption of phenol (a: adsorption of phenol onto modified pumice stone, $b$ : modified LECA)

\subsection{Structural characteristics of pumice and LECA}

In this study, SEM was used to determine the adsorbent apparent properties. Figure $7(a-d)$ represents the SEM image of raw pumice and LECA and their modified form with iron nanoparticles. Figure $7 a$ is related to the raw pumice and it is clarifying that the primary raw pumice has a porous surface. After modification of raw pumice with iron nanoparticles (Figure 7b), it is observed that the initial pumice surface has altered and the initial porous surfaces are not clearly visible. This is because the pumice outer surface has coated with iron nanoparticles (Dursun and Kalayci, 2005). These changes are clearly visible on the surface of the LECA before and after modification with iron nanoparticles.
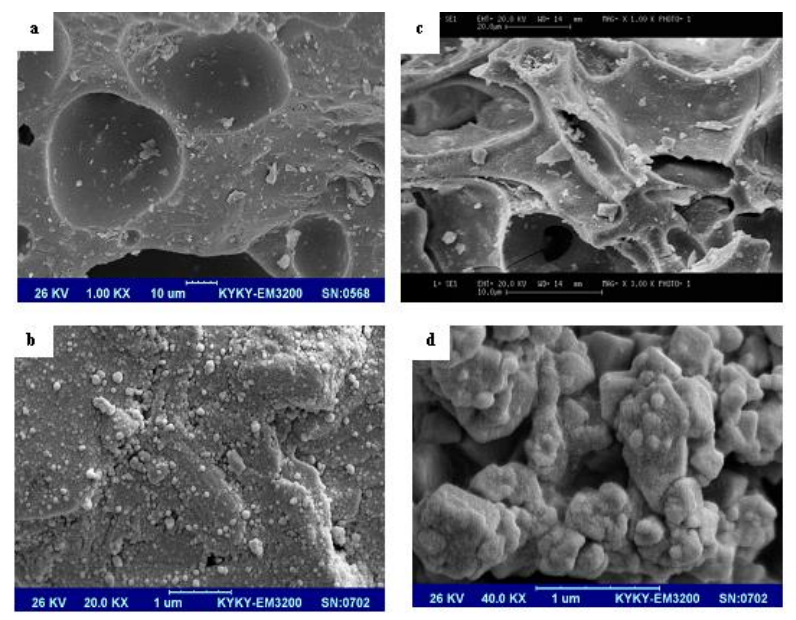

Figure 7. Scanning electron micrograph (SEM) image (a: natural pumice stone, b: natural LECA, c: modified pumice stone, $d$ : modified LECA)

\section{Conclusion}

This study is a basic-applied study in which pumice stone and LECA were used as the effective adsorbents in phenol removal from aqueous solution. In this study, the effects of independent variables such as $\mathrm{pH}$ (3-5-7-9-11), initial concentration of phenol (10-50 mg/l), contact time (10-60 min) and different dosage of pumice and LECA $(0.2-1 \mathrm{~g} / 100 \mathrm{cc})$ was investigated on the efficiency of phenol removal in a batch reactor. The results of the experiments showed that the removal efficiency of phenol has a direct relationship with increasing the contact time and the adsorbent dosage and has a reverse relationship with increasing the $\mathrm{pH}$ and the initial concentration of phenol. The study of isotherm and kinetic models showed that the experimental data of the phenol adsorption process were correlated with with Freundlich $\left(R_{\text {pumice }}^{2}=0.9749, R^{2}\right.$ LECA $\left.=0.9487\right)$ and Pseudo-second order $\left(R_{\text {pumice }}^{2}=0.9745, R_{\text {LECA }}^{2}=0.9486\right)$ models. The results of this study indicate that the modified pumice and LECA have a high ability to remove the phenol and use of this process can be considered as a suitable method for the removal of phenol in aqueous solutions because these adsorbents are inexpensive and their modification method is easy.

\section{References}

Abdelwahab O. and Amin N. (2013), Adsorption of phenol from aqueous solutions by Luffa cylindrica fibers: kinetics, isotherm and thermodynamic studies, The Egyptian Journal of Aquatic Research, 39(4):215-223.

Abussaud B., Asmaly H.A., Saleh T.A., Gupta V.K. and Atieh M.A. (2016), Sorption of phenol from waters on activated carbon impregnated with iron oxide, aluminum oxide and titanium oxide, Journal of Molecular Liquids, 213, 351-359. 
Ahmaruzzaman M. (2008), Adsorption of phenolic compounds on low-cost adsorbents: a review, Advances in Colloid and Interface Science, 143(1-2), 48-67.

Akbal F. (2005a), Sorption of phenol and 4-chlorophenol onto pumice treated with cationic surfactant, Journal of Environmental Management, 74(3), 239-244.

Akbal F. (2005b), Adsorption of basic dyes from aqueous solution onto pumice powder, Journal of Colloid and Interface Science, 286(2), 455-458.

Aksu Z. and Yener J. (2001), A comparative adsorption/biosorption study of mono-chlorinated phenols onto various sorbents, Waste Management, 21(8), 695-702.

Asgari G., Roshani B. and Ghanizadeh G. (2012), The investigation of kinetic and isotherm of fluoride adsorption onto functionalize pumice stone, Journal of Hazardous Materials, 217, 123-132.

Asmaly H.A., Ihsanullah, Abussaud B., Saleh T.A., Laoui T., Gupta V.K., et al. (2016), Adsorption of phenol on aluminum oxide impregnated fly ash, Desalination and Water Treatment, 57(15), 6801-6808.

Behnamfard A. and Salarirad M.M. (2009), Equilibrium and kinetic studies on free cyanide adsorption from aqueous solution by activated carbon, Journal of Hazardous Materials, 170(1), 127-133.

Dehghani M.H., Mostofi M., Alimohammadi M., McKay G., Yetilmezsoy K. and Albadarin A.B., et al. (2016), Highperformance removal of toxic phenol by single-walled and multi-walled carbon nanotubes: kinetics, adsorption, mechanism and optimization studies, Journal of Industrial and Engineering Chemistry, 35, 63-74.

Din A.T.M., Hameed B. and Ahmad A.L. (2009), Batch adsorption of phenol onto physiochemical-activated coconut shell. Journal of Hazardous Materials, 161(2-3), 1522-1529.

Dursun A.Y. and Kalayci C.S. (2005), Equilibrium, kinetic and thermodynamic studies on the adsorption of phenol onto chitin, Journal of Hazardous Materials, 123(1-3), 151-157.

EPA U. (2009), National Recommended Water Quality Criteria, United States Environmental Protection Agency', Office of Water, Office of Science and Technology

Eren E. (2009), Removal of lead ions by Unye (Turkey) bentonite in iron and magnesium oxide-coated forms, Journal of Hazardous Materials, 165(1-3), 63-70.

Hameed B. and Rahman A. (2008), Removal of phenol from aqueous solutions by adsorption onto activated carbon prepared from biomass material, Journal of Hazardous Materials, 160(2-3), 576-581.

Heibati B., Yetilmezsoy K., Zazouli M.A., Rodriguez-Couto S., Tyagi I. and Agarwal S., et al. (2016), Adsorption of ethidium bromide $(\mathrm{EtBr})$ from aqueous solutions by natural pumice and aluminium-coated pumice, Journal of Molecular Liquids, 213, 41-7.

Kırbıyık Ç., Pütün A.E., Pütün E. (2017), Equilibrium, kinetic, and thermodynamic studies of the adsorption of Fe (III) metal ions and 2, 4-dichlorophenoxyacetic acid onto biomassbased activated carbon by $\mathrm{ZnCl} 2$ activation, surfaces and Interfaces, 8, 182-192.

Kučić D., Miljanić S. and Rožić M. (2011), Sorption of methylene blue onto orange and lemon peel, The Holistic Approach to Environment, 1(2), 41-51.

Lee S.-M., Laldawngliana C. and Tiwari D. (2012), Iron oxide nano-particles-immobilized-sand material in the treatment of $\mathrm{Cu}$ (II), $\mathrm{Cd}$ (II) and $\mathrm{Pb}$ (II) contaminated waste waters, Chemical Engineering Journal, 195, 103-111.

Li Y., Du Q., Liu T., Sun J., Jiao Y. and Xia Y., et al. (2012), Equilibrium, kinetic and thermodynamic studies on the adsorption of phenol onto graphene, Materials Research Bulletin, 47(8), 1898-1904.

Lorenc-Grabowska E., Gryglewicz G. and Diez M. (2013), Kinetics and equilibrium study of phenol adsorption on nitrogenenriched activated carbons, Fuel, 114, 235-243.

Malakootian M., Nouri J. and Hossaini H. (2009), Removal of heavy metals from paint industry's wastewater using Leca as an available adsorbent, International Journal of Environmental Science \& Technology, 6(2), 183-190.

Messele S., Soares O., Órfão J., Bengoa C. and Font J. (2017), Zero-valent iron supported on nitrogen-doped carbon xerogel as catalysts for the oxidation of phenol by fenton-like system, Environmental Technology,1-8.

Nkansah M.A., Christy A.A., Barth T. and Francis G.W. (2012), The use of lightweight expanded clay aggregate (LECA) as sorbent for PAHs removal from water, Journal of Hazardous Materials, 217, 360-365.

Panuccio M.R., Sorgonà A., Rizzo M. and Cacco G. (2009), Cadmium adsorption on vermiculite, zeolite and pumice: batch experimental studies, Journal of Environmental Management, 90(1), 364-374.

Qadeer R. and Rehan A.H. (2002), A study of the adsorption of phenol by activated carbon from aqueous solutions, Turkish Journal of Chemistry, 26(3), 357-362.

Rao J. and Viraraghavan T. (2002), Biosorption of phenol from an aqueous solution by Aspergillus niger biomass. Bioresource Technology, 85(2), 165-71.

Rengaraj S., Moon S.-H., Sivabalan R., Arabindoo B. and Murugesan V. (2002), Agricultural solid waste for the removal of organics: adsorption of phenol from water and wastewater by palm seed coat activated carbon, Waste Management, 22(5), 543-8.

Sepehr M.N., Sivasankar V., Zarrabi M. and Kumar M.S. (2013), Surface modification of pumice enhancing its fluoride adsorption capacity: an insight into kinetic and thermodynamic studies, Chemical Engineering Journal, 228, 192-204.

Shokoohia R., Jafarib A.J., Dargahia A. and Torkshavanda Z. (2017), Study of the efficiency of bio-filter and activated sludge (BF/AS) combined process in phenol removal from aqueous solution: determination of removing model according to response surface methodology (RSM). Desalination and Water Treatment, 77, 256-263.

Varghese S., Vinod V. and Anirudhan T. (2004), Kinetic and equilibrium characterization of phenols adsorption onto a novel activated carbon in water treatment.

Wang X.-L., Shen J., Niu Y.-X., Wang Y.-G., Liu G. and Sheng Q.-T. (2018), Removal of phenol by powdered activated carbon prepared from coal gasification tar residue, Environmental Technology, 39(6), 694-701.

Wang X.S., Zhou Y., Jiang Y. and Sun C. (2008), The removal of basic dyes from aqueous solutions using agricultural byproducts, Journal of Hazardous Materials, 157(2-3), 374-385.

W.E. Federation and A.P.H. Association (2005), Standard Methods for the Examination of Water and Wastewater, American Public Health Association (APHA): Washington, DC, USA 
Zhu H., Jiang R., Xiao L. and Zeng G. (2010), Preparation, characterization, adsorption kinetics and thermodynamics of novel magnetic chitosan enwrapping nanosized $\psi$-Fe2O3 and multi-walled carbon nanotubes with enhanced adsorption properties for methyl orange, Bioresource Technology, 101(14), 5063-5069. 